\title{
Effects of tool offset and reversed metal flow on mechanical properties of dissimilar friction stir welded T-lap joints between AA7075 and AA5083
}

\author{
Hao Dinh DUONG*, Masakazu OKAZAKI** and Tra Hung TRAN*** \\ *Graduate school of Mechanical Engineering, Nagaoka University of Technology \\ 1603-1 Kamitomioka-machi, Nagaoka-shi, Niigata 940-2188, Japan \\ E-mail: s167012@stn.nagaokaut.ac.jp \\ **Department of Mechanical Engineering, Nagaoka University of Technology \\ 1603-1 Kamitomioka-machi, Nagaoka-shi, Niigata 940-2188, Japan \\ ***Department of Engineering Mechanics, Nha Trang University \\ 02 Nguyen Dinh Chieu street, Nha Trang city, Vietnam
}

Received: 9 October 2019; Revised: 11 December 2019; Accepted: 20 January 2020

\begin{abstract}
The effects of tool offset and the reversed metal flow induced by a double-pass friction stir welding (FSW) on the welding interface characteristics were investigated in a dissimilar thickness T-lap joint between 7075-T651 and 5083-H116 aluminum alloys. The performance of the joint was evaluated by the skin and stringer tensile tests. The experimental results showed that the bonding interface could be improved by applying double-pass welding which the tool was offsetted toward advancing side. An employment of the double-pass welding significantly improved the strength so that the joint efficiency reached about $90 \%$ in comparison with the 5083 base metal strength while the tensile strength of the joint produced by the single-pass welding was quite low. The kissing bond defects were found to be the main culprit in the tensile behavior of the T-lap joint. The reversed metal flow and the gap distance between pin and die played a key role in the formation of the welding interface.
\end{abstract}

Keywords : Dissimilar T-lap joint, Double-pass friction stir welding, Tool offset, Reversed metal flow, Mechanical properties, Kissing bond defects

\section{Introduction}

Recently, the fuel efficiency and saving the materials have been becoming great challenges to manufacturer. The uses of lightweight alloys such as titanium, aluminum, magnesium, etc., and their dissimilar joint are considered as one of the suitable solutions. However, the weldability of these alloys by the conventional welding methods has not been satisfactory. As presented by Jesus et al. (2014), the application of metal inert gas (MIG) welding for AA5083-H111 significantly reduced the fatigue strength of T-joint. Muñoz et al. (2008) showed that the yield strength of the joint decreased about 50\% compared to base metal for using tungsten inert gas (TIG) welding. These welding methods are difficult to be applied in some aluminum alloys such as AA2xxx and AA7xxx series, due to the formations of solidification cracking and porosity (Lippold and Lin, 1996; Li et al., 2017). A solid-state joining technique with namely Friction Stir Welding (FSW) is expected to perform a good joint (Thomas et al., 1991; Tokisue et al., 2005; Mishra and Ma, 2005). In fact, Ahmed et al. (2017) have shown the high strength of dissimilar butt-joint of FSWed AA7075/AA5083 with about $87 \%$ in comparison with the base metal. A similar result was also performed by Khan et al. (2017) for AA2219 and AA7475 aluminum alloys.

The T-joints those are usually composed of stringer and skin plates are one of the common joints in the railway tankers, aircraft wing-box and ship panel structures, as studied by Chintapalli et al. (2010) and Wang et al. (2013). Here, the stringer is designed as stronger members to form frame structure while the skin is light shell covering outside. 
A combination of two aluminum alloys may be useful for some structures with multiple functions; e.g. high durability of AA7075 for stringer and good corrosion resistance of AA5083 for skin, respectively.

The weldability of FSWed T-lap joint has been evaluated by using single-pass welding in literatures. For example, Acerra et al. (2010) and Astarita et al. (2012) revealed dissimilar FSWed T-joint while Fratini et al. (2007) focused on the similar FSWed T-joint. However, the strength of the joint was not satisfactory. The effects of some FSW parameters on the T-joint characteristics have been investigated to improve the joint efficiency from the viewpoints of the metal flow (Fratini et al., 2009), welding speed (Cui et al., 2012; Hao et al., 2019), and tool geometry (Jesus et al., 2018). In spite of these, the T-lap joint efficiency has still been unsatisfactory, especially in stringer loading test. This is due to formation of some undesirable defects in the joint; e.g. tunnel, kissing bond, zigzag line, bonding line, oxide line defects, etc., those directly degrade the mechanical properties of the T-joint. Among these defects, the kissing bonds at two corner fillets seem to be too hard to be eliminated only by changing welding parameters, especially when it is formed at retreating side. In order to minimize this type of defect, Feistauer et al. (2018) tried to use the second-pass welding by keeping the similar direction of FSW tool rotation but the reserved welding direction. Consequently, the size of kissing bond defects was significantly reduced. From these works, it is obviously that the control of welding interface is a key issue in the strength of the FSWed T-lap joint.

The aim of this work is to improve the strength of dissimilar metal FSWed T-lap joint between AA7075 and AA5083. For this purpose, special attention was put on the effects of both the tool offset and the reversed material flow induced by the double-pass welding on the welding interface characteristics.

\section{Experimental procedures}

\subsection{Materials and welding tool}

In this work, two aluminum alloys were selected to fabricate the dissimilar T-lap joint (Fig. 1a), i.e. 5083-H116 (as denoted by AA5083) for the skin part and 7075-T651 (as denoted by AA7075) for the stringer part, respectively. The skin and stringer plates were prepared in the dimensions of $300 \times 150 \times 3.0 \mathrm{~mm}$ and $300 \times 50 \times 8.2 \mathrm{~mm}$, respectively. The chemical composites and mechanical properties of two alloys are listed in Table 1 and Table 2, respectively. The plate surfaces were ground and polished by steel brush and abrasive SiC paper, respectively to eliminate oxidation layers before welding. The dissimilar T-lap joint was fabricated by a cylinder pin with the shoulder diameter of $24.0 \mathrm{~mm}$. The detail dimension of the welding tool is summarized in Fig. $1 \mathrm{~b}$ and Table 3. The pin axis alignment was set at a constant with the tilt angle of $2.0^{\circ}$. The tool shoulder was penetrated into the surface of skin plate with the depth of $0.2 \mathrm{~mm}$ during the welding process. Through this work, the welding speed and rotational speed were chosen by $100 \mathrm{~mm} / \mathrm{min}$ and $400 \mathrm{rpm}$, respectively, based on the previous work (Hao et al., 2019).

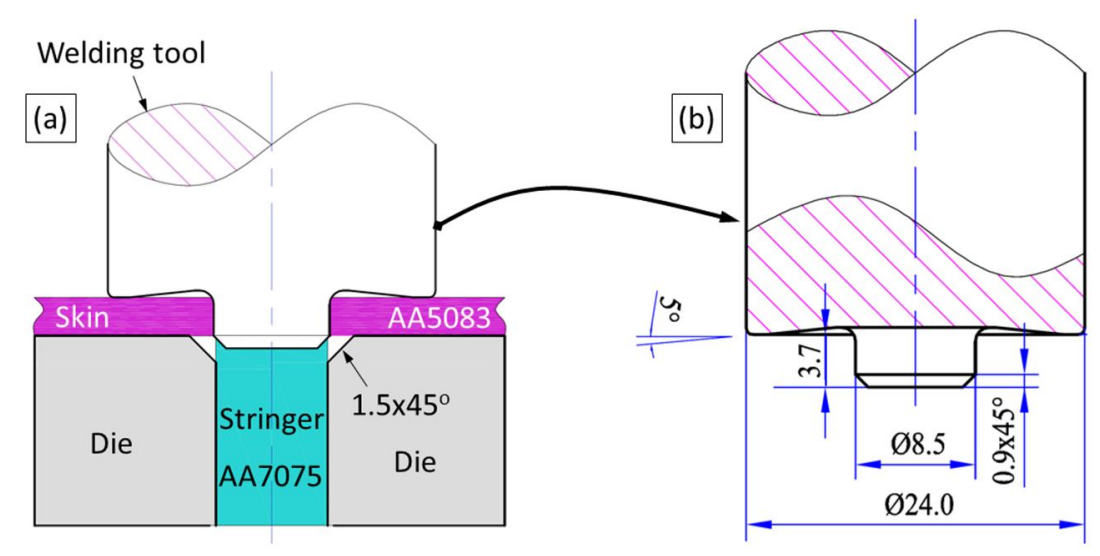

Fig. 1 (a) Schematic view of T-lap joint and (b) welding tool geometry (dimensions in mm).

Table 1 Chemical compositions (wt\%) of AA5083-H116 and AA7075-T651 used.

\begin{tabular}{l|l|l|l|l|l|l|l|l|l}
\hline Compositions & $\mathrm{Si}$ & $\mathrm{Fe}$ & $\mathrm{Cu}$ & $\mathrm{Mn}$ & $\mathrm{Mg}$ & $\mathrm{Cr}$ & $\mathrm{Zn}$ & $\mathrm{Ti}$ & $\mathrm{Al}$ \\
\hline AA5083-H116 & 0.4 & 0.4 & 0.1 & $0.4-1.0$ & $4.0-4.9$ & $0.05-0.25$ & 0.25 & 0.15 & Bal. \\
\hline AA7075-T651 & 0.5 & 0.7 & $1.2-2.0$ & 0.3 & $2.1-2.9$ & $0.18-0.40$ & 6.1 & 0.2 & Bal. \\
\hline
\end{tabular}


Table 2 Mechanical properties of AA5083-H116 and AA7075-T651.

\begin{tabular}{c|c|c|c|c}
\hline $\begin{array}{c}\text { Mechanical } \\
\text { properties }\end{array}$ & $\begin{array}{c}\text { Yield strength } \\
(\mathrm{MPa})\end{array}$ & $\begin{array}{c}\text { Ultimate tensile strength } \\
(\mathrm{MPa})\end{array}$ & $\begin{array}{c}\text { Shear strength } \\
(\mathrm{MPa})\end{array}$ & $\begin{array}{c}\text { Vicker hardness } \\
\left(\mathrm{kgf} / \mathrm{mm}^{2}\right)\end{array}$ \\
\hline AA5083-H116 & 230 & 320 & 180 & 95 \\
\hline AA7075-T651 & 500 & 570 & 320 & 180 \\
\hline
\end{tabular}

Table 3 Welding tool geometry and investigated location.

\begin{tabular}{c|c|c|c|c|c|c|c|c}
\hline \multicolumn{4}{c|}{ Tool geometry $(\mathrm{mm})$} & \multicolumn{4}{c}{ Representative locations for investigating (mm) } \\
\hline$\varnothing$ Shoulder & Concave shoulder & $\varnothing$ Pin & Pin length & Offsetting to RS & Center & \multicolumn{3}{c}{ Offsetting to AS } \\
\hline 24.0 & $5^{\circ}$ & 8.5 & 3.7 & -0.8 & -0.4 & 0.0 & 0.4 & 0.8 \\
\hline
\end{tabular}

\subsection{Production of T-lap joint}

The T-lap joints were fabricated by applying double-pass FSW, combining with a tool offset method. Here, the second-pass FSW had the same welding direction but reversed tool rotation with the first-pass welding, as schematically displayed in Fig. 2a. This implies, after the second-pass FSW, a new advancing side (as denoted by AS2) and retreating side (as denoted by RS2) were produced at the retreating side (as denoted by RS1) and advancing side (as denoted by AS1) of the first-pass welding, respectively. In the tool offset method, as illustrated in Fig. 2a, the welding tool was located at an eccentric position to the centerline of the T-joint for both the first- and second-pass FSWs. The offset intervals were the experimental variable in this work; those had distances from 0.0 to $1.0 \mathrm{~mm}$ toward both the AS (as denoted by plus "+" value) and the RS (as denoted by minus "-" value) as illustrated in Figs. 2b-d.

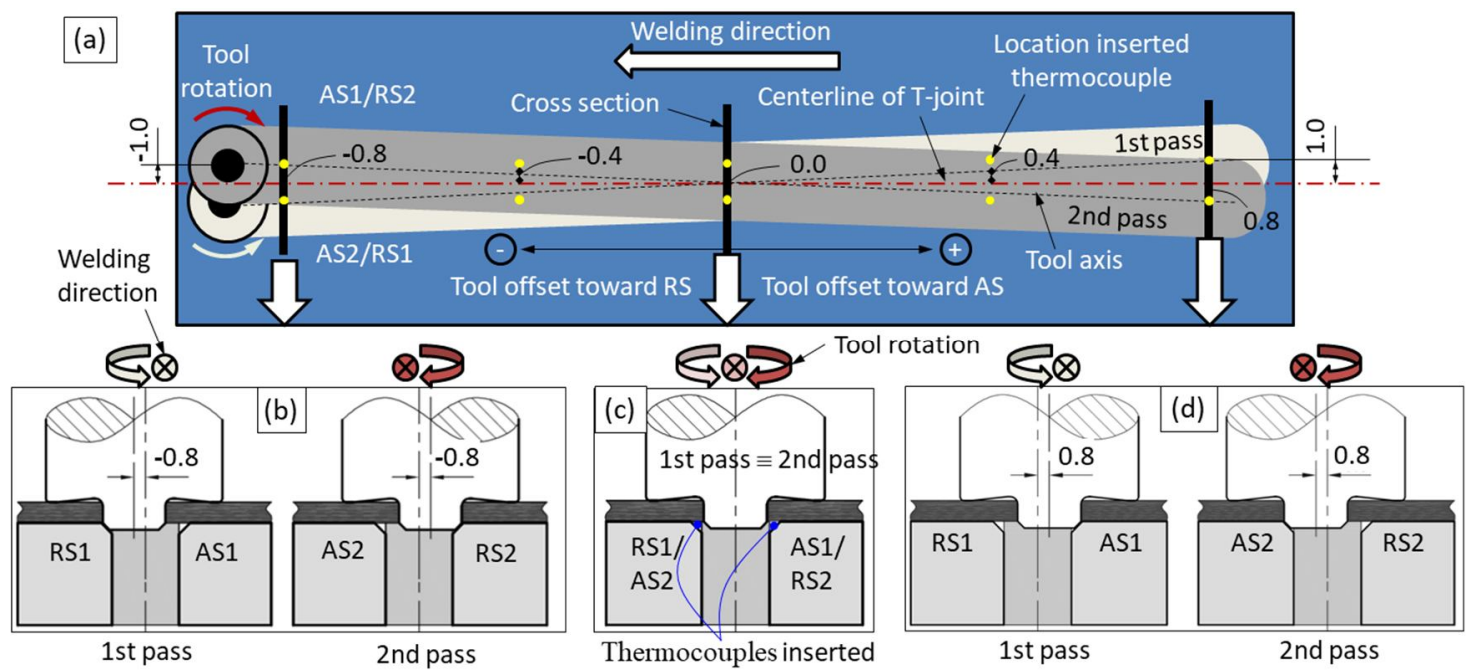

Fig. 2 (a) Schematic diagrams of tool offset and reversed metal flow induced during FSW process and the positions of welding tool at offsetting (b) $-0.8 \mathrm{~mm}$, (c) $0.0 \mathrm{~mm}$, and (d) $0.8 \mathrm{~mm}$.

\subsection{Process analysis}

Since the temperature history provides an important knowledge to evaluate the performance of the FSW, it was monitored by the K-type thermocouples at multiple sites as indicated in Fig. 2. The performance of the FSW at each site was evaluated from the multiple aspects: size of kissing bond, microstructure characteristics, hardness profile, and tensile strength. On these measurements, a special attention was paid to the effects of the reversed metal flow and tool offset. Here, the hardness map was measured along the centerline of skin and stringer plates by means of a micro Vickers indenter under 0.2 $\mathrm{kgf}$ load for $10 \mathrm{~s}$. The tensile strength was evaluated by two types of tensile tests under a strain rate of $1.0 \mathrm{~mm} / \mathrm{min}$; One is the tensile test with loading direction along the skin part, following the ASTM E08 standards (2004) (Fig. 3a, as denoted by "skin test"), and the other is along the stringer part (Fig. 3b, as denoted by "stringer test") with the support of a jig made of steel material. 


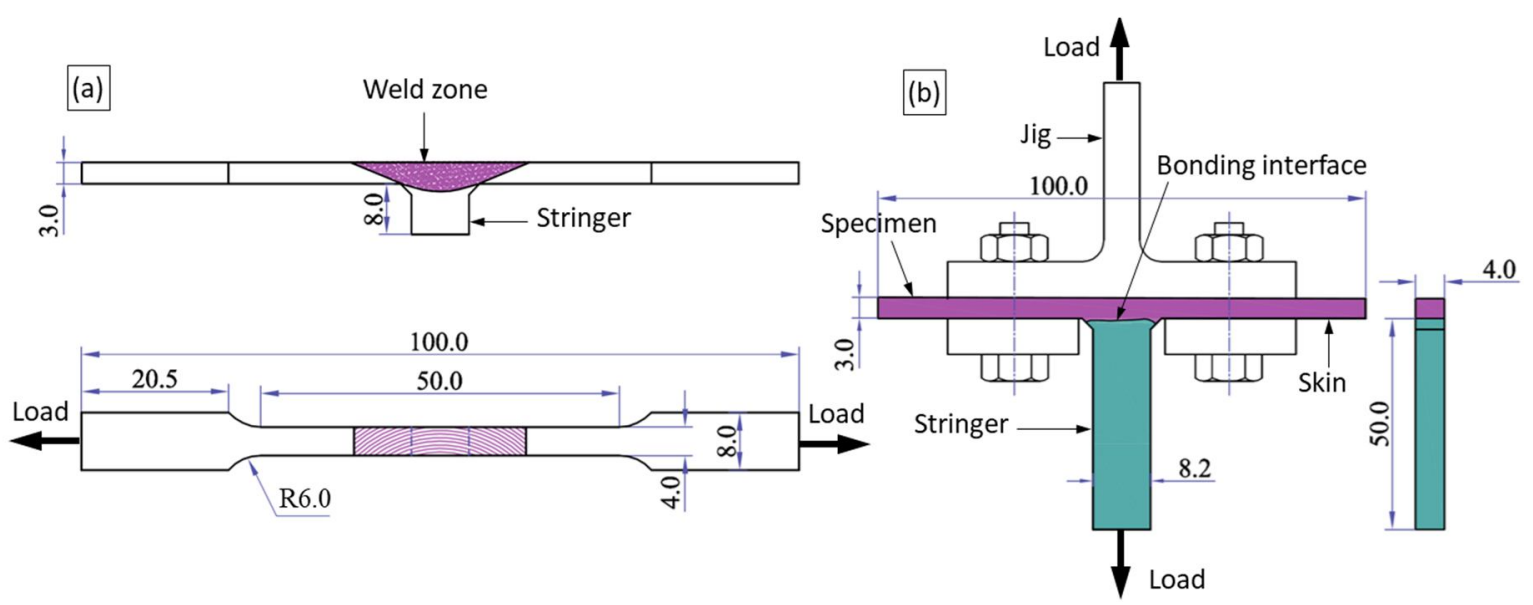

Fig. 3 Evaluation of T-lap joint: (a) skin and (b) stringer tests (dimensions in mm).

\section{Results}

\subsection{Temperature during FSW process}

The temperature history under the first- and second-pass FSWs via the Fig. 2 method is shown in Figs. 4a-b. There was no significant difference in peak temperature under the present welding conditions. A slight difference in peak temperature between the AS and RS was found. Here, the peak value at the AS was about $450^{\circ} \mathrm{C}$ while that at the RS was slightly lower than that at the AS by about $20^{\circ} \mathrm{C}$. Based on above results, it can be concluded that the effects of reversed or multiple metal stirring and the tool offset on the welding temperature were insignificant during the FSW process.
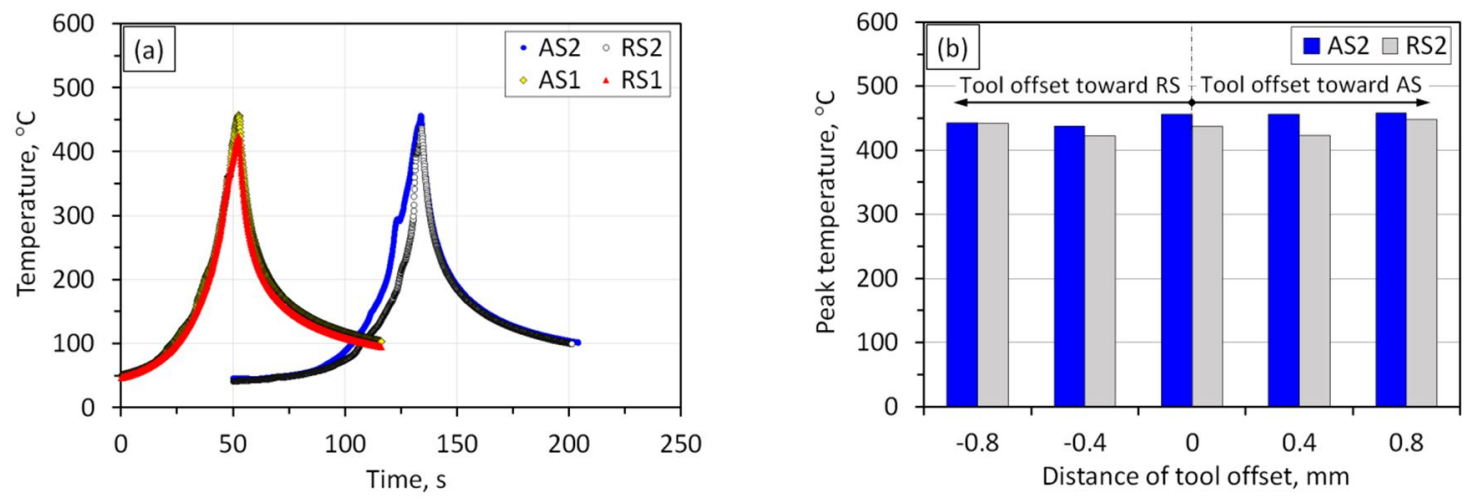

Fig. 4 (a) Temperature curve at the AS and RS of first- and second-pass weldings at tool offset of $0.0 \mathrm{~mm}$ and (b) peak temperature under various distances of tool offset.

\subsection{Effects of reversed material flow and tool offset on welding interface characteristics}

\subsubsection{Effect of reversed material flow}

The effect of the reversed tool rotation to the primary FSW process on the welding interface feature is shown in Fig. 5 for the case of tool offset of $0.0 \mathrm{~mm}$. Here, the welding interface can be postulated as boundary between skin and stringer plates after the welding process. It can be seen that two types of bondings were achieved along the welding interface; i.e. an interface associating with kissing bond defects (as denoted by KBs) with oxide layer, and bonding interface with little oxide layer, as reported by Hao et al. (2019). It is worthy to note that the welding interface produced by the single-pass FSW was associated with pronounced KBs at the RS1 (Fig. 5a). The application of double-pass welding with reversed tool rotation significantly changed the morphologies of interface in both the KBs and bonding interface (Fig. 5d).

The sizes of the KBs and bonding interface were measured on the basis of the size of oxide layer, as illustrated by the white arrow marks in Figs. 5b,c,e,f. The results are summarized in Figs. 6a,b in terms of the curve length of the KBs and the effective bonded width (as denoted by $W$ ) in the single- and double-pass FSW. It is found from Fig. 6 that 
the KBs size at the RS1 dramatically decreased by applying the double-pass welding (corresponding to the AS2 in Fig. 6a). By reducing the size of the KBs, the effective bonded width between the skin and stringer was dramatically improved, as seen in Fig. 6b. This phenomenon may be attributed to successful metal flow as suggested by Fig. $5 \mathrm{~d}$ and will be discussed again in the next section.

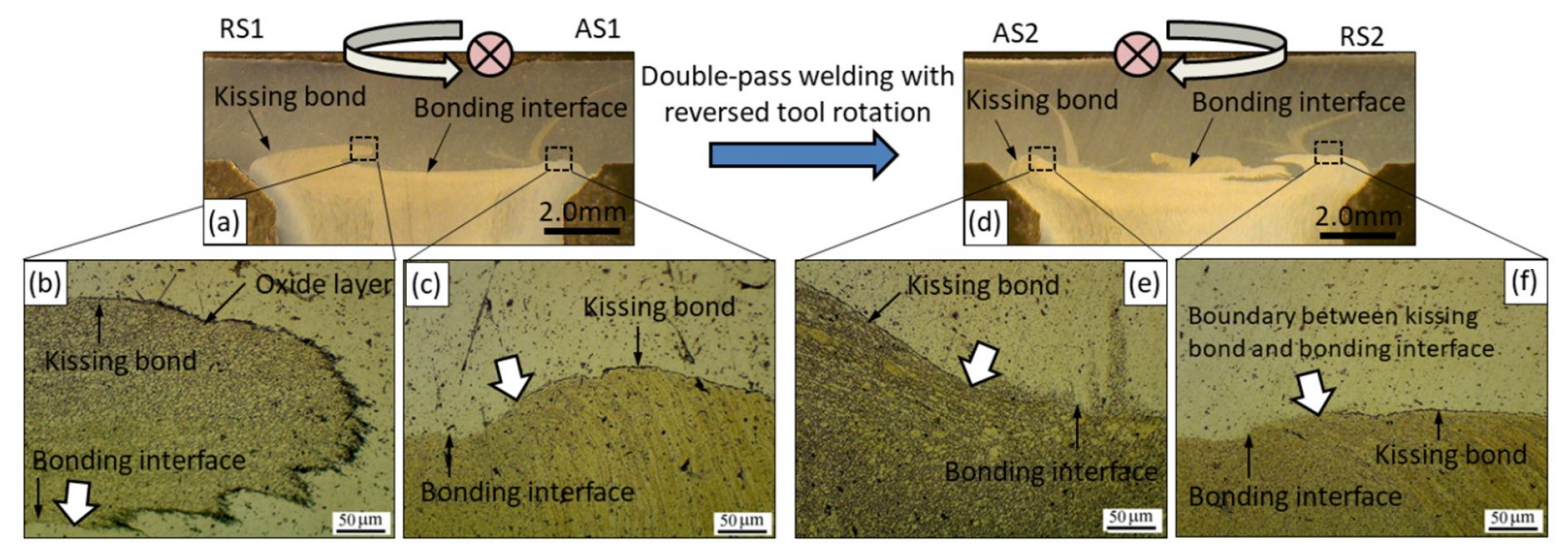

Fig. 5 Image of welding interface produced by (a-c) single- and (d-f) double-pass FSWs at the tool offset of $0.0 \mathrm{~mm}$.
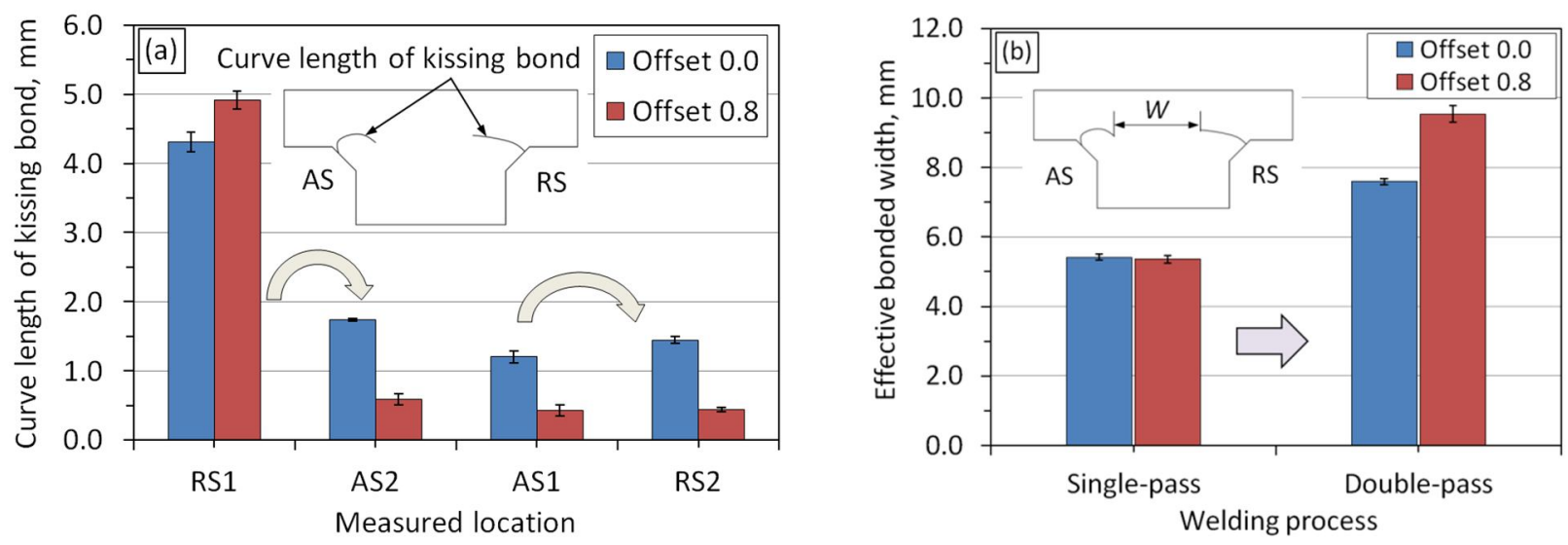

Fig. 6 Effect of reversed material flow on (a) curve lengths of KBs and (b) effective bonded width under single- and double-pass FSWs.

\subsubsection{Effect of tool offset}

Figure 7 shows the images of macro- and micro-structures of welding interface produced by the double-pass FSW under the various distances of tool offset. Upon changing the direction and the distance of tool offsets, the morphology of welding interface was significantly changed. By offsetting the tool toward the RS, the geometry of the KBs tended upward from the two corner fillets and then moved deeply into weld center (Figs. 7a-b). This phenomenon might degrade the mechanical properties of the FSWed T-lap joint, as will be discussed in the next section. In contrast, the KBs were significantly minimized due to offsetting tool toward the AS (Figs. 7c-d). In addition, the material welded interface seems to be mixed better when the tool was offsetted to the AS. As noted from Fig. 7f, the mixture of two aluminum alloys was observed along the interface. This result can bring about the higher bonding strength of interface compared to that of interface without mixing two materials (Fig. 7e).

The curve length of the KBs and the value of effective bonded width were directly measured on the specimens to quantitatively evaluate the effect of the distance of tool offset on the welding interface characteristic as shown in Fig. 8. It is found that although the volume of pin penetration into two corner fillets was symmetrical through the centerline of the T-joint, the tendencies of both KBs and bonding interface sizes were opposite. Here, increasing the distance of tool offset toward the RS seems to increase the curve length of the KBs, whereas the KBs were impressively decreased by offsetting the tool to the AS. Another worthy finding is that the curve length of the KBs at the AS2 was longer than that at the RS2 in all cases. 


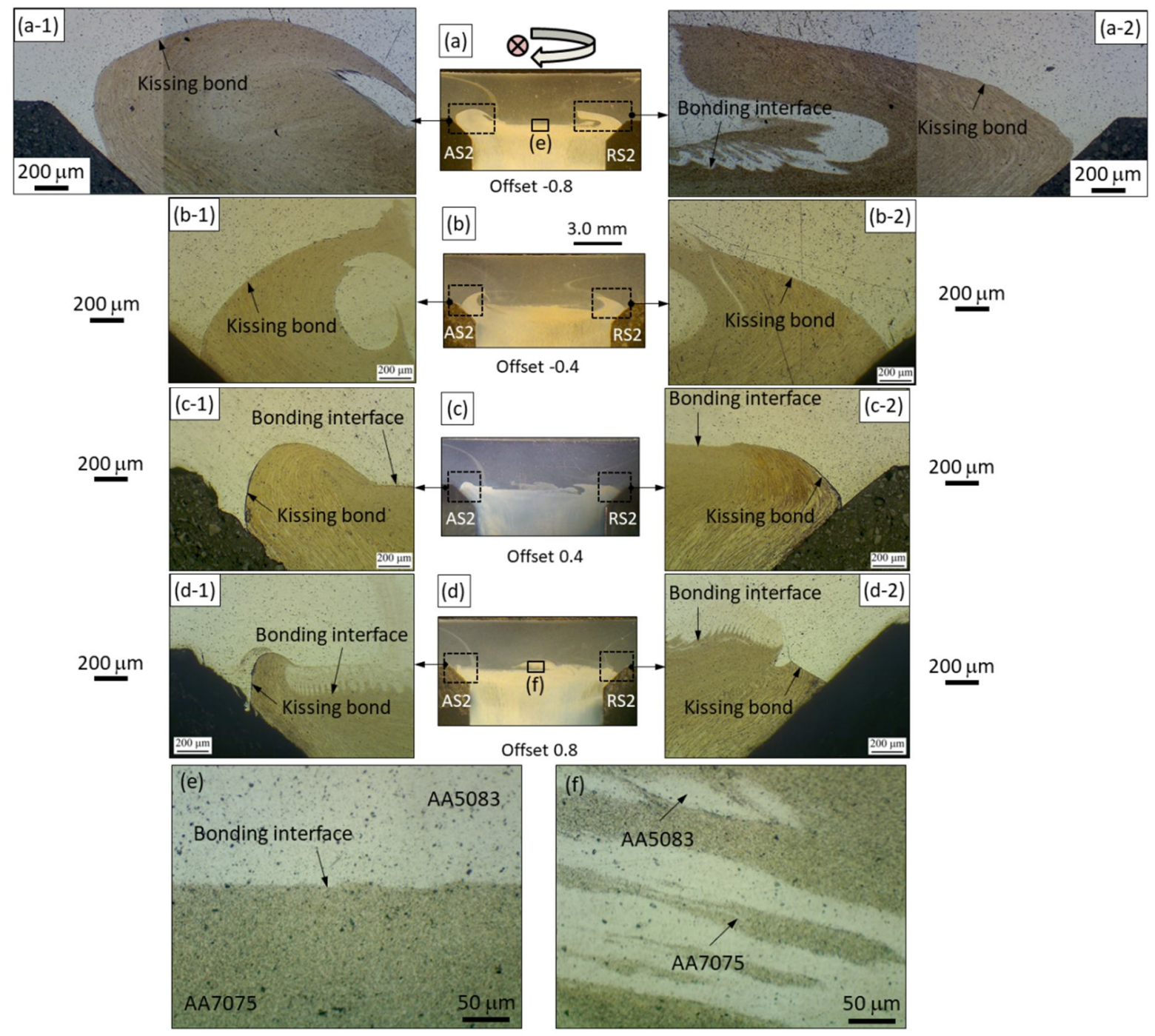

Fig. 7 (a-d) Macro- and (e,f) micro-structures of welding interface produced under various distances of tool offsets.
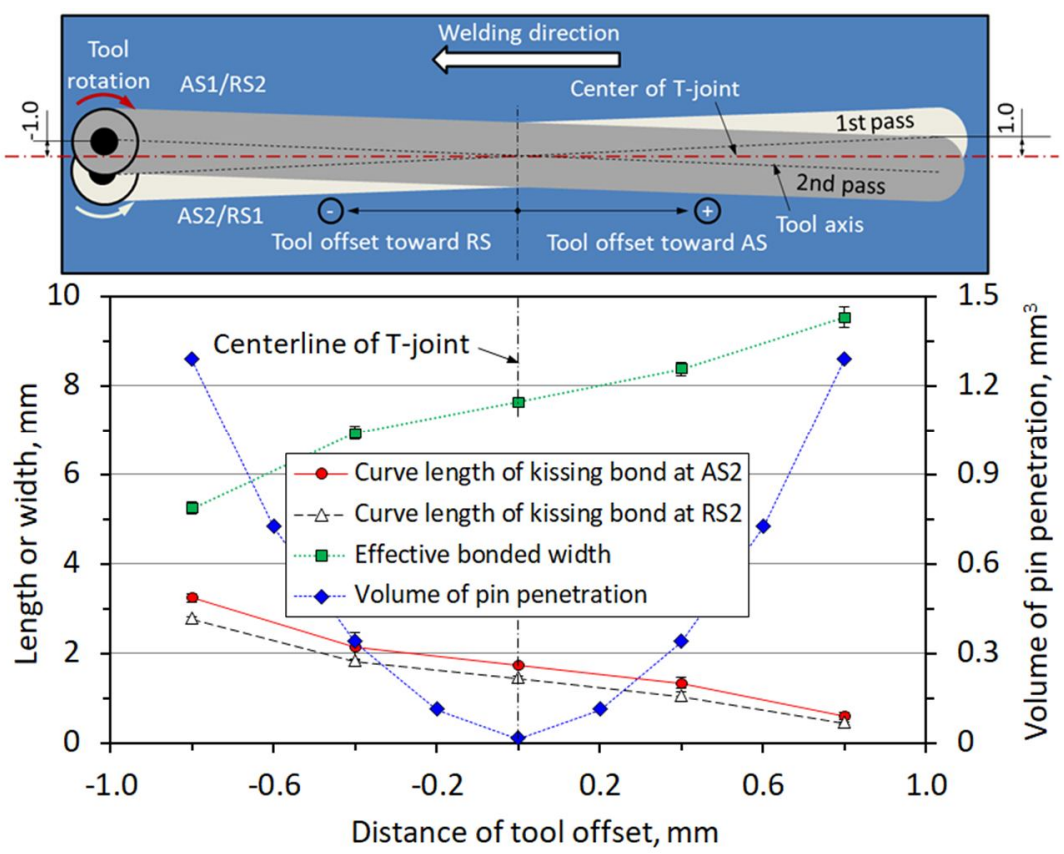

Fig. 8 Effect of distances of tool offset on the curve length of KBs and effective bonded width. 


\subsection{Mechanical properties of T-lap joint \\ 3.3.1 Microhardness profile}

The effects of the double-pass FSW and the tool offset on the hardness profile along the skin and stringer plates of the FSWed T-lap joint are shown in Figs. 9a and 9b, respectively. It seems that the hardness of the RS and AS was reversed by offsetting tool (Fig. 9a). This result might concern to the different temperature in the AS and RS, resulting from two factors. Firstly, the temperature in the AS is higher than that in the RS, as seen in Fig. 4. Secondly, the reversed tool rotation, or reversed metal flow was applied in the double-pass regimes. It is also interesting, the microhardness map along the stringer seems to be insensitive to the welding conditions (Fig. 9b). The hardness value inside and around welding zone was lower than that of the base alloys.
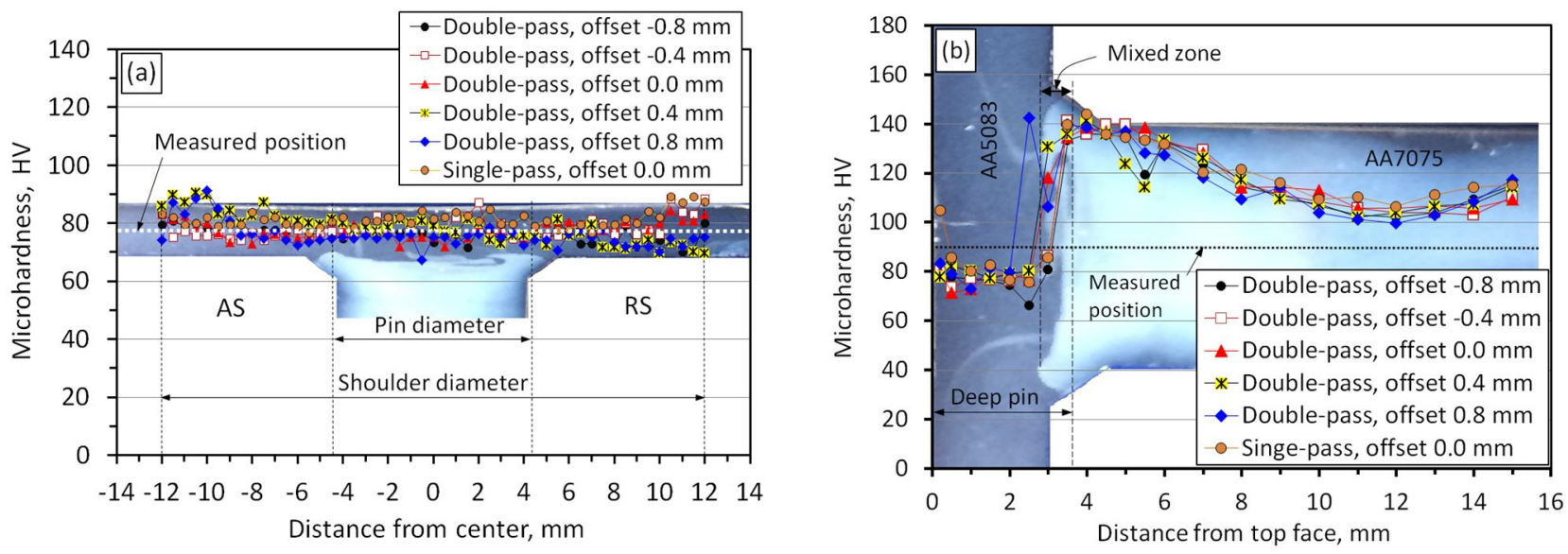

Fig. 9 Effect of various welding conditions on hardness profile along: (a) skin and (b) stringer.

\subsubsection{Tensile test}

The representative stress-strain curves in the skin test under various welding conditions are shown in Fig. 10a. It is worthy to note that the tensile strength and the rupture strain were significantly improved by employing the double-pass FSW, especially upon offsetting toward the AS, as shown in Fig. 10b. The maximum stress and rupture strain of the joint were attained by about $290 \mathrm{MPa}$ (90\% joint efficiency) and 12\%, respectively when the tool offset was set up by $0.8 \mathrm{~mm}$.

The representative load-displacement curves in the stringer test are displayed in Fig. 11a. Dissimilar to the skin test, most of the curves were discontinuous associating with "pop-in" phenomenon, except the case when the tool offset was set up by $0.8 \mathrm{~mm}$. It is worthy to note that the strength of the T-lap joint was significantly improved but the rupture strength was reduced by employing the double-pass FSW by offsetting toward the AS, as shown in Fig. 11b. These results might be attributed by the formation of the KBs.

Figure 12a shows the fracture location of specimens under skin tests. It can be seen that most of the specimens cracked in the AS2, particularly at the KBs and HAZ regions. The failure of T-lap joint under stringer test was more complex than that under the skin test. The existence of the KBs had big contribution to this failure of specimens, as shown in Fig. 12b. Here, the crack dominantly initiated from the KBs associating with "pop-in" phenomenon, as seen in Fig. 11a. After the "pop-in", the applied load increased again before the specimen was broken completely. Thus total ductility of the joint in the stringer test depends on both the KBs morphology and the welded zone properties.

The representative fractography after the rupture is shown in Fig. 12c that the specimen was produced at the tool offset of $-0.8 \mathrm{~mm}$. Two zones can be identified on the fracture surface: KBs zone and bonding interface zone. The fracture surface in the KBs region displayed a smooth facet while the remaining region associated with the ductile dimples mode. 

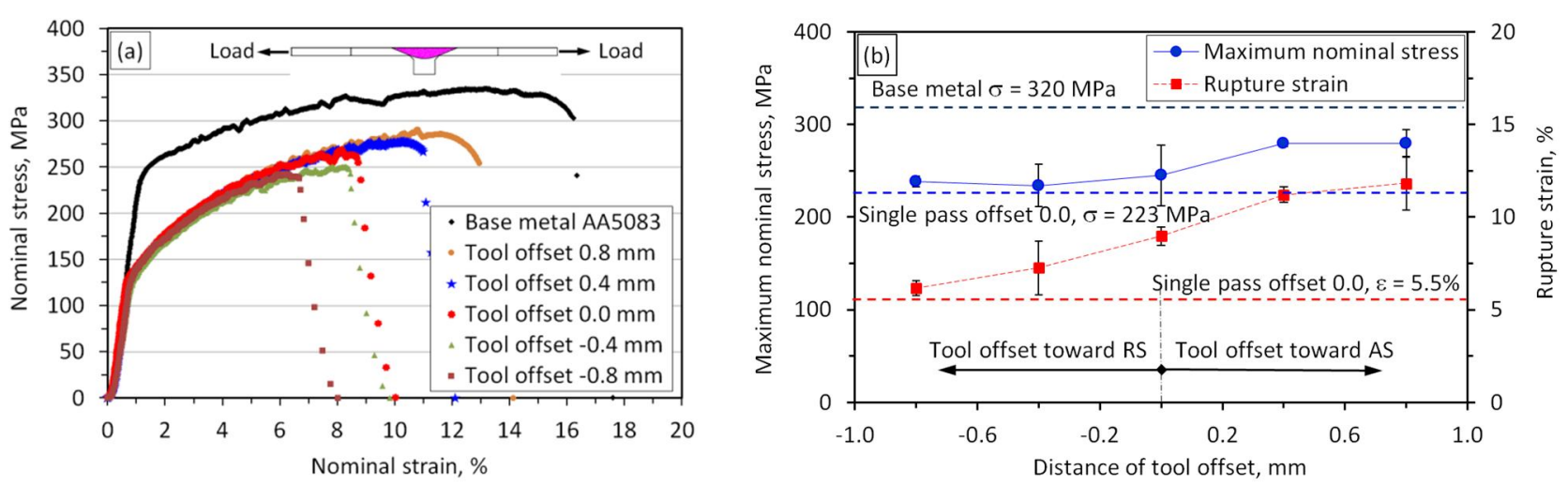

Fig. 10 Mechanical properties of the joint under the skin test: (a) nominal stress-strain curves and (b) maximum nominal stress and rupture strain.
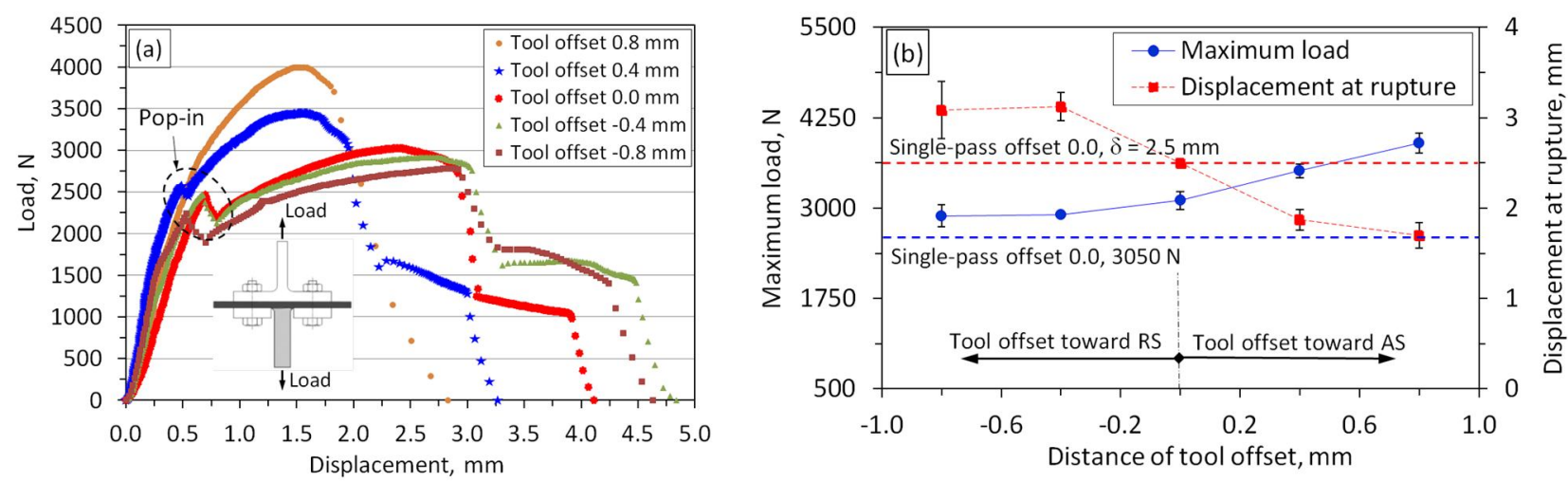

Fig. 11 Mechanical properties of the joint under the stringer test: (a) load-displacement curves and (b) maximum load and displacement at rupture.

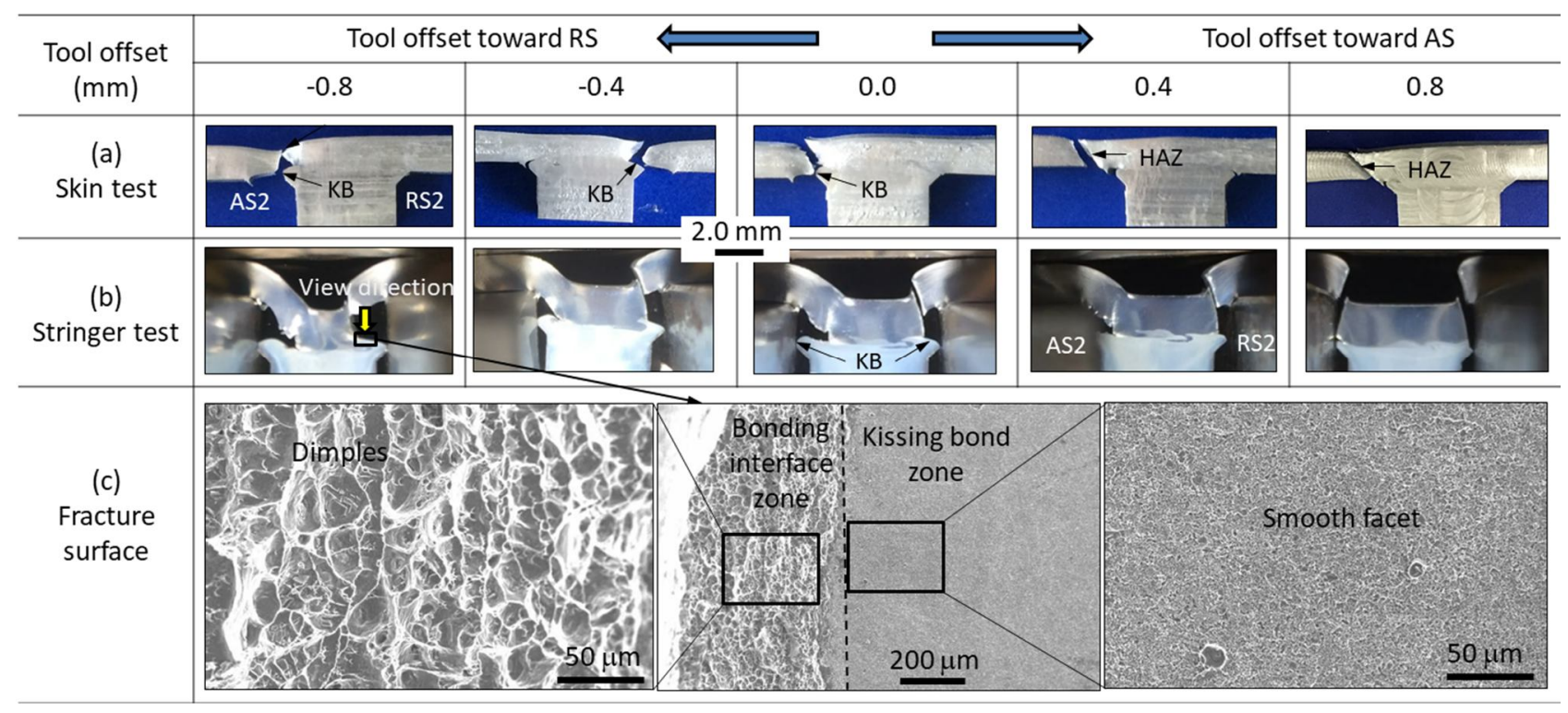

Fig. 12 Fracture locations of specimens under (a) skin and (b) stringer tests, and (c) the fracture morphology of the KBs and bonding interface zone as marked in Fig. 12b. 


\section{Discussion}

As suggested in previous section, it was useful to apply the double stirring process with the tool offset toward the AS to achieve the higher strength not only in the skin but also in the stringer tests. These results are summarized in Fig. 13, from different aspects in terms of the effective bonded width (as denoted by $W$ ) and effective skin thickness (as denoted by $t_{\mathrm{AS}}$ and $t_{\mathrm{RS}}$ ) those are defined by the length, as illustrated in Fig. 13. The application of tool offset towards the AS would lead to the larger values of both $W, t_{\mathrm{AS}}$, and $t_{\mathrm{RS}}$, resulting in higher tensile properties as shown in Figs. 10 and 11. In other words, the quality of the T-joint strongly depends on some appropriate methods to enable to minimize the size of the KBs which had little bonding strength (Oosterkamp et al., 2004; Sato et al., 2005).

Following the references by Guerra et al. (2002) and Buffa et al. (2008), the material flow in a single FSW process can be shown in Fig. 14. Here the material at the front AS seems to be involved into tool pin while that at the back RS is nearly escaped from tool pin. This might lead to the mixture of material at the AS1 was more severe than that at the RS1, as reported by Feistauer et al. (2018), Donatus et al. (2015), and Buffa et al. (2008). In addition, the KBs at the RS1 must be achieved by horizontal material flow that moved from the RS1 to the AS1, as reported by Hao et al. (2019). In other words, a mere single-pass FSW is not enough to minimize the KBs in the T-lap joint. A double-pass FSW accompanying with the reversed tool rotation and tool offset can compensate the above disadvantage, especially at the RS1 as postulated by Fig. 15. It is clear that the KBs are often formed after the first-pass FSW, as observed in Figs. 15a1,a2,b1,b2. After the second-pass FSW, the KBs were minimized due to the difference in pin location when the appropriate tool offset was undertaken. The KBs were minimized at the AS2 by the tool offset of $0.8 \mathrm{~mm}$ (Figs. $15 \mathrm{b3}, \mathrm{b} 4)$, whereas the large KBs remained at the RS2 by the inappropriate tool offset of $-0.8 \mathrm{~mm}$ (Figs. 15a3,a4).

Figure 16 at the same time suggests an importance of gap distance, $\delta$ when the tool pin was offsetted toward the AS and is geometrically expressed by

$$
\delta=(D-x) \sin \alpha \quad \text { with } x \leq D
$$

where $D(\mathrm{~mm})$ is a distance between the body pin and the edge of die, and $x(\mathrm{~mm})$ is the distance of tool offset and $\alpha$ is the chamfer angle of die. Figure 17 expresses the relationship between the representative KBs distance, $d$ and the gap distance, $\delta$ in this work, suggesting the usefulness of set up of moderate $\delta$ to minimize the KBs.

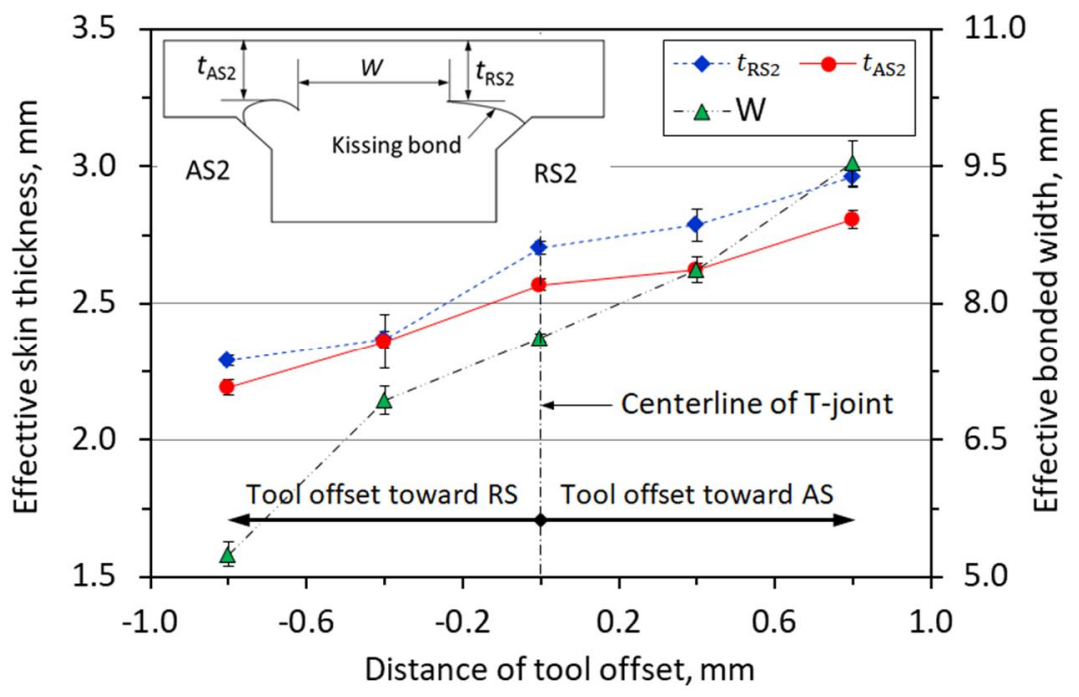

Fig. 13 Effect of distances of tool offset on the effective skin thickness and effective bonded width. 


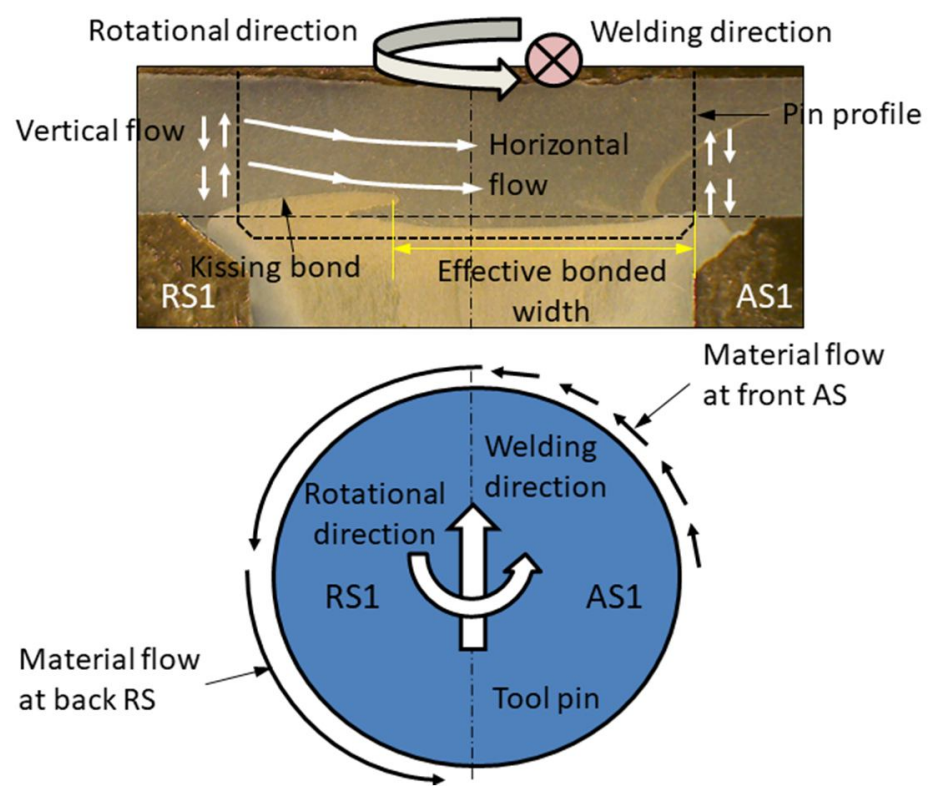

Fig. 14 Schematic illustration of material flow in single-pass FSWed process.

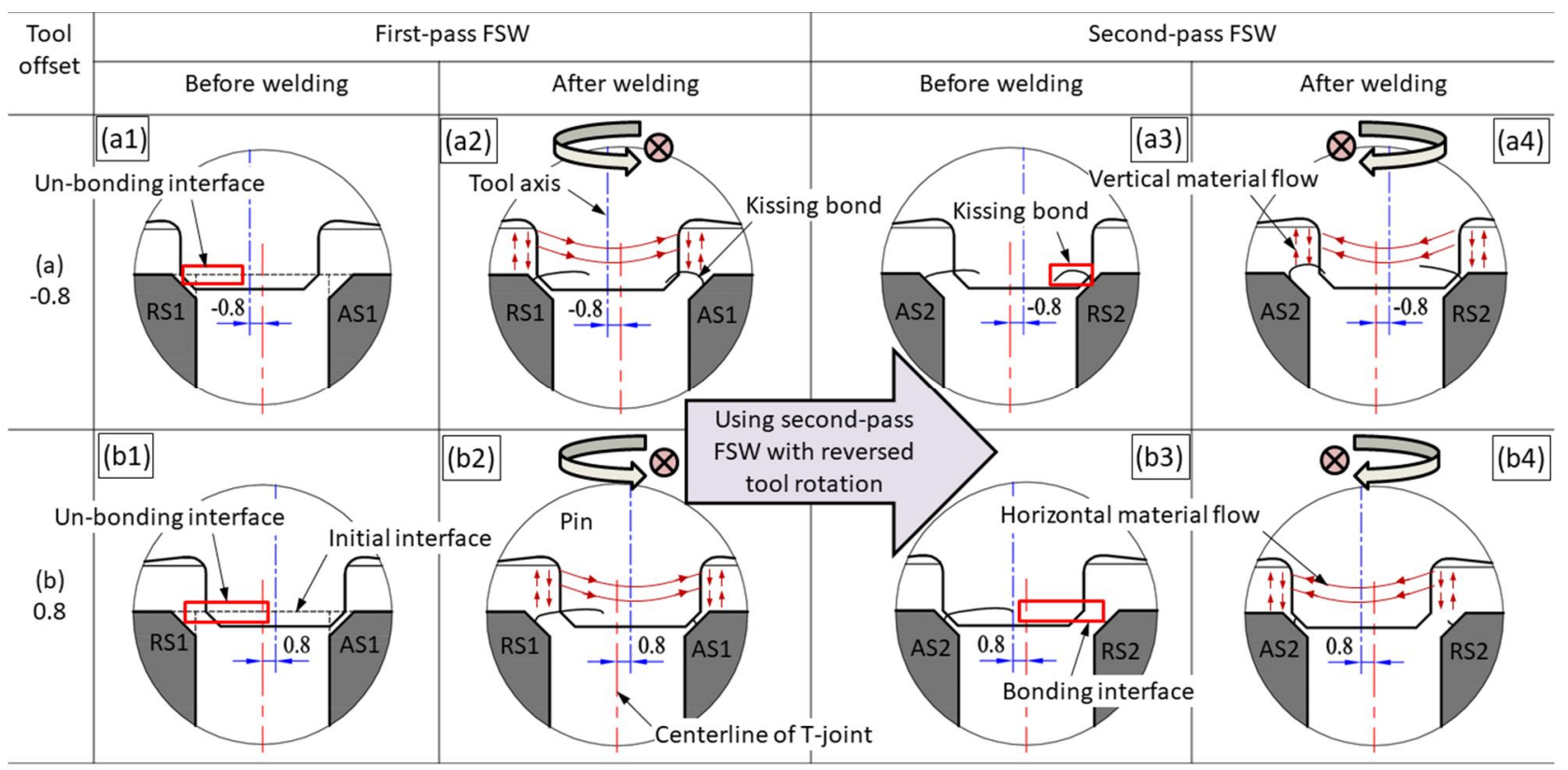

Fig. 15 Schematic illustration of KBs formation in the double-pass FSW by the tool offsets of (a) -0.8 and (b) $0.8 \mathrm{~mm}$.

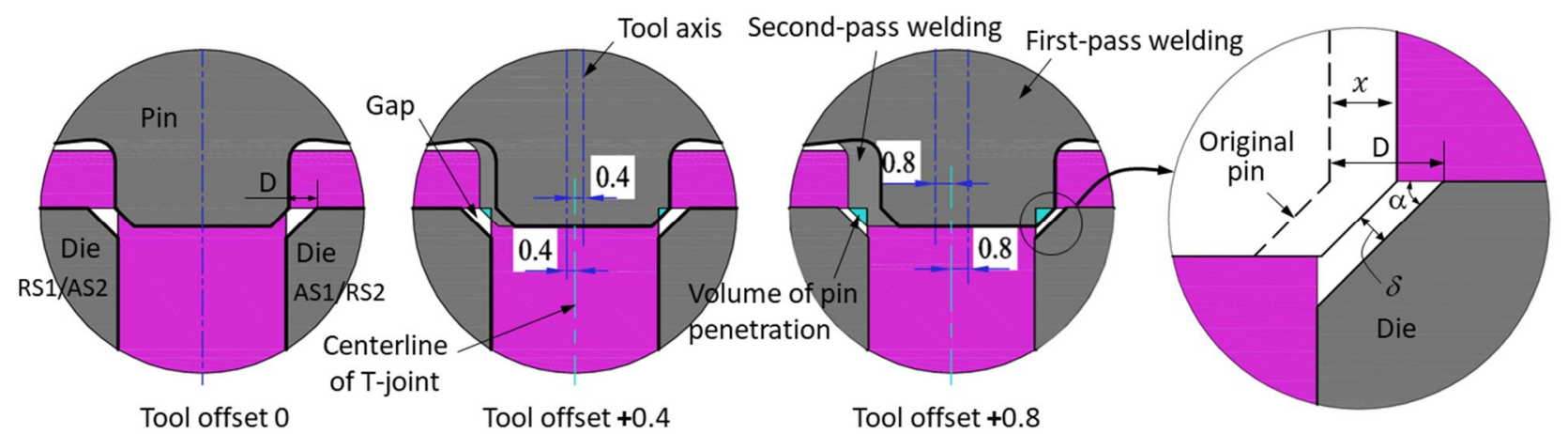

Fig. 16 Schematic illustration of pin penetration into corner fillets at the various distances of tool offset. 


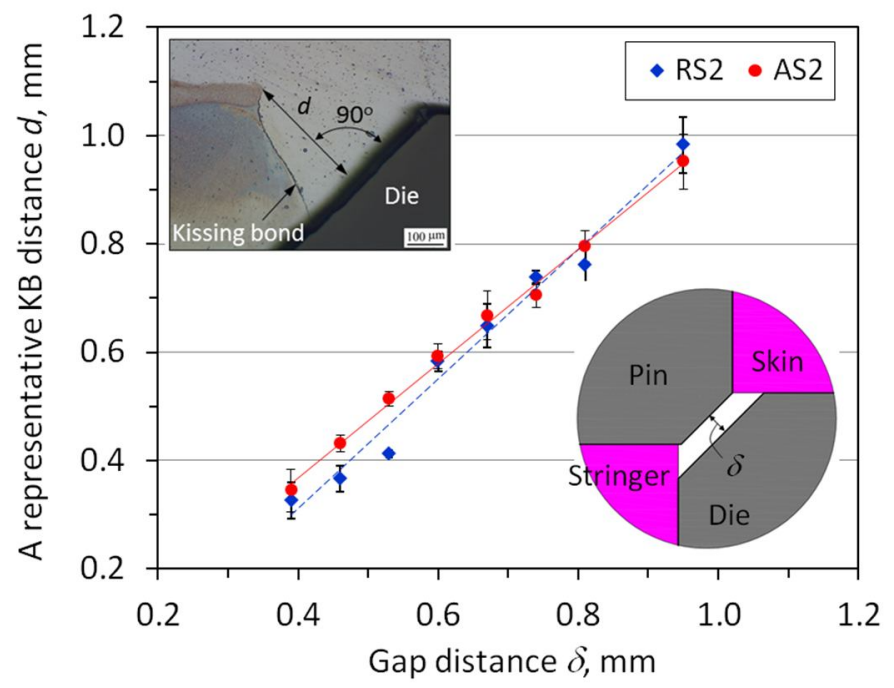

Fig. 17 Relationship between the representative KBs distance and the gap distance.

\section{Conclusions}

The dissimilar thickness FSWed T-lap joint between AA7075 and AA5083 was fabricated by using both single- and double-pass FSWs. The effects of the tool offset and the reversed material flow induced by the double-pass FSW on the formation of welding interface and the mechanical properties of the T-lap joint were investigated. The following conclusions were reached:

(1) Applying the double-pass FSW which induced a reversed material flow could significantly improve the quality of the welding interface; decrease in the KBs size and increase in the effective bonded width, without insignificant change in welding temperature and hardness profile.

(2) The tool position and asymmetric material flow had a significant influence on the KBs formation. By combining the reversed material flow and the tool offset toward the AS, the KBs size could be significantly minimized at both the AS and the RS. Applying the tool offset of $0.8 \mathrm{~mm}$ toward the AS, the joint efficiency was reached approximately $90 \%$ in comparison with the 5083 base metal for both the skin and stringer tests.

(3) The above behavior was reasonably interpreted by the metal flow during the double-pass FSW process. The gap distance played an important role in the formation of the KBs.

\section{Acknowledgements}

The authors acknowledge the financial support for this work from the Ministry of Education, Culture, Sports, Science, and Technology (MEXT). One of co-authors, M. Okazaki would like to be also thankful to the Japan Society for the Promotion of Science (JSPS) for financial support through Grant-in-aid \#16H02304.

\section{References}

Acerra, F., Buffa, G., Fratini, L. and Troiano, G., On the FSW of AA2024-T4 and AA7075-T6 T-joints: an industrial case study, International Journal of Advanced Manufacturing Technology, Vol.48, (2010), pp.1149-1157.

Ahmed, M. M. Z., Sabbah Ataya, El-Sayed Seleman, M. M., Ammar, H. R. and Ahmed, E., Friction stir welding of similar and dissimilar AA7075 and AA5083, Journal of Materials Processing Technology, Vol.242, (2017), pp.77-91.

Annual Book of ASTM Standards, Test methods for tension testing of metallic materials, E08, (2004), ASTM International.

Astarita, A., Squillace, A., Scala, A. and Prisco, A., On the Critical Technological Issues of Friction Stir Welding T-Joints of Dissimilar Aluminum Alloys, Journal of Materials Engineering and Performance, Vol.21, No.8 (2012), pp.1763-1771. 
Buffa, G., Fratini, L., Micari, F. and Shivpuri, R., Material Flow in FSW of T-joints: Experimental and Numerical Analysis, International Journal of Material Forming, Vol.1, No.1 (2008), pp.1283-1286.

Chintapalli, S., Elsayed, M. S. A., Sedaghati, R. and Abdo, M., The development of a preliminary structural design optimization method of an aircraft wing-box skin-stringer panels, Aerospace Science and Technology, Vol.14, No.3 (2010), pp.188-198.

Cui, L., Yang, X., Zhou, G., Xu, X. and Shen, Z., Characteristics of defects and tensile behaviors on friction stir welded AA6061-T4 T-joints, Materials Science and Engineering A, Vol.543, (2012), pp.58-68.

Donatus, U., Thompson, G. E., Zhou, X., Wang, J. and Beamish, K., Flow patterns in friction stir welds of AA5083 and AA6082 alloys, Materials and Design, Vol.83, (2015), pp.203-213.

Feistauer, E. E., Bergmann, L. A. and dos Santos, J. F., Effect of reverse material flow on the microstructure and performance of friction stir welded T-joints of an Al-Mg alloy, Materials Science and Engineering A, Vol.731, (2018), pp.454-464.

Fratini, L., Micari, F., Squillace, A. and Giorleo, G., Experimental characterization of FSW T-joints of light alloys, Key Engineering Materials, Vol.344, (2007), pp.751-758.

Fratini, L., Buffa, G., Micari, F. and Shivpuri, R., On the material flow in FSW of T-joints: Influence of geometrical and technological parameters, International Journal of Advanced Manufacturing Technology, Vol.44, No.5-6 (2009), pp.570-578.

Guerra, M., Schmidt, C., McClure, J. C, Murr, L. E. and Nunes, A. C, Flow patterns during friction stir welding, Materials Characterization, Vol.49, No.2 (2002), pp.95-101.

Hao, D. D., Okazaki, M., and Tra, H. T., Effect of welding parameters on mechanical properties of friction stir welded T-lap dissimilar metal joints between 7075 and 5083 aluminum alloys, JSME-Mechanical Engineering Journal, Vol.6, No.4 (2019), DOI: 10.1299/mej.19-00091.

Jesus, J. S., Costa, J. M., Loureiro, A. and Ferreira, J. M., Assessment of friction stir welding aluminium T-joints, Journal of Materials Processing Technology, Vol.255, (2018), pp.387-399.

Jesus, J. S., Loureiro, A., Costa, J. M. and Ferreira, J. M., Effect of tool geometry on friction stir processing and fatigue strength of MIG T welds on Al alloys, Journal of Materials Processing Technology, Vol.214, (2014), pp.2450-2460.

Khan, N. Z., Siddiquee, A. N., Khan, Z. A. and Mukhopadhyay, A. K., Mechanical and microstructural behavior of friction stir welded similar and dissimilar sheets of AA2219 and AA7475 aluminium alloys, Journal of Alloys and Compounds, Vol.695, (2017), pp.2902-2908.

Li, H., Zou, J., Yao, J. and Peng, H., The effect of TIG welding techniques on microstructure, properties and porosity of the welded joint of 2219 aluminum alloy, Journal of Alloys and Compounds, Vol.727, (2017), pp.531-539.

Lippold, J. C. and Lin, W., Weldability of commercial Al-Cu-Li alloys, Materials science forum, Vol.217-222, (1996), pp.1685-1690.

Mishra, R. S. and Ma, Z. Y., Friction stir welding and processing, Materials Science and Engineering R, Vol.50, (2005), pp.1-78.

Muñoz, A. C., Rückert, G., Huneau, B., Sauvage, X. and Marya, S., Comparison of TIG welded and friction stir welded Al-4.5Mg-0.26Sc alloy, Journal of Materials Processing Technology, Vol.197, (2008), pp.337-343.

Oosterkamp, O., Oosterkamp, L. D. and Nordeide, A., 'Kissing bond' phenomena in solid-state welds of aluminum alloys, Welding Journal, Vol.83, No.8 (2004), pp.225-231.

Sato, Y. S., Takauchi, H., Park, S. H. C. and Kokawa, H., Characteristics of the kissing-bond in friction stir welded Al alloy 1050, Materials Science and Engineering A, Vol.405, (2005), pp.333-338.

Thomas, W. M., Nicholas, E. D., Needham, J. C., Murch, M. G., Temple-Smith, P. and Dawes, C. J., Friction-stir butt welding, International Patent Application PCT/GB92/02203 and GB Patent Application 9125978.8, UK Patent Office, London, December 6, (1991).

Tokisue, H. ed, "Friction stir welding", Nikkan Kogyo Publisher (2005) (in Japanese).

Wang, J., Rashed, S., Murakawa, H. and Luo, Y., Numerical prediction and mitigation of out-of-plane welding distortion in ship panel structure by elastic FE analysis, Marine Structures, Vol.34, (2013), pp.135-155. 